\title{
LIGAÇÕES INTERMEDIÁRIAS E REPRESENTAÇÃO PERSPÍCUA EM WITTGENSTEIN
}

\author{
Rafael Lopes Azize \\ Universidade Federal do Piauí
}

\begin{abstract}
The notion of intermediate links, which reveal themselves through comparisons between language games, indicates the very objects of incidence of conceptual investigation - whose context of pertinent elements is continuously expanded by Wittgenstein. In its negative operation, such notion is prophylactic against the philosophical attitude of searching for an ultimate and definitive ground for the problem of the form of presentation. In its negative operation, it is the conceptual tool that will allow for the crucial step of relativising the closed propositional systems. But perhaps the full reach of the use of 'intermediate links' is shown when we inquire whether the diversity of panoramic scenes of the perspicuous mode of presentation of concepts - whose outline makes up the bulk of the philosophical "new method" proposed by Wittgenstein - more than including intermediary cases, in an adventitious fashion, is constituted by these.
\end{abstract}

Key-words: Intermediate cases, perspicuous presentation, analysis (Philosophy), use, concept, Wittgenstein.

Resumo: A noção de ligações intermediárias de sentido, que se revelam através de comparações entre jogos de linguagem, indica os objetos excelsos de incidência de uma investigação conceitual - cujo contexto de elementos pertinentes é progressivamente ampliado por Wittgenstein. Na sua operação negativa, tal noção é profilática contra a atitude filosófica de se buscar um solo último e definitivo para o problema da forma de apresentação. Na sua operação positiva, é a ferramenta conceitual que permitirá o passo crucial de se relativizar os sistemas proposicionais fechados. Mas talvez o pleno alcance do uso de 'ligações intermediárias' se revele ao nos perguntarmos se diversidade de cenas panorâmicas da forma perspícua de representação de conceitos -cerne do "novo método" filosófico proposto por Wittgenstein- não apenas inclui casos intermediários, de forma acessória, mas, mais do que isso, é constituída por esses.

Palavras-chave: Ligações intermediárias, representação perspícua, análise (Filosofia), uso, conceito, Wittgenstein. 
O objetivo deste artigo é investigar a operação de um conceito wittgensteiniano a que os comentadores não costumam dedicar muita atenção: a noção de ligações intermediárias. De fato, não parece irrazoável deixar de o priorizar numa lista de conceitos centrais do filósofo vienense. No entanto, é possível que a cooperação desse conceito se revele essencial ao funcionamento de algumas das noções fulcrais da constelação conceitual do Wittgenstein tardio - como, por exemplo, jogos de linguagem, forma de vida, gramática e terapia. É o que nos propomos a estudar.

A noção de Zwischengliedern, casos ou ligações intermediárias que se revelam através de comparações entre jogos de linguagem, pretende circunscrever o tipo de objetos excelsos de incidência da investigação conceitual, ou seja, do trabalho filosófico por excelência tal como o entende Wittgenstein. Ou melhor, as ligações intermediárias circunscrevem o processo de investigação conceitual, ainda que não o terminus desta - cujo contexto está em vias de ser ampliado por Wittgenstein em meados dos anos 30. Mas a importância da noção de ligação intermediária pode também ser estabelecida tendo-se em vista um movimento mais amplo da obra do filósofo. Uma passagem do MS 157a (1934-7) pode servir de ensejo a uma indicação de em que sentido isso pode ser visto:

A ideia da essência, quando queríamos fornecer a essência da proposição, não era simplesmente [a de] uma descrição do que se denota com essa palavra, mas, antes, [a de] exprimir um Último, [a de] fornecer a claridade última sobre algo incomparável. Apresentá-lo (não uma descrição) claramente e de uma vez por todas. ${ }^{1}$ (MS 157a, pp. 56v-57r; grifo nosso)

O essencialismo da "antiga maneira de pensar" do filósofo prendia-se, portanto, por um lado, com a ilusão de uma apresentação clara da essência da realidade, ou da linguagem, de forma tal que o problema posto pela forma de apresentação ficasse resolvido de uma vez por todas. Para isso, seria preciso

\footnotetext{
${ }_{1}^{1}$,Die Idee des Wesens, wenn wir das Wesen des Satzes angeben wollten, war nicht einfach, eine Beschreibung dessen was man mit diesem Wort bezeichnet, sondern sie war, ein Letztes zu sagen, eine letzte Klarheit zu schaffen über das Unvergleichliche. Es klar (keine Beschr.) ein für alle mal darzustellen".
} 
postular os elementos últimos como definitivos (do ponto de vista da sua participação num mundo esquemático), e a sua apresentação como igualmente definitiva. A lógica vista como algo sublime -e não como um componente possível do simbolismo linguístico- inspira, aqui, a noção de uma linguagem perfeita que esteja ao serviço de uma tal apresentação, ao mesmo tempo em que dê acesso à estrutura do que por esse meio se apresenta. Por outro lado, tratava-se de lançar luz sobre um fim das cadeias de razões que não pudesse mais ser comparado com o que quer que fosse, i.e., ali onde aspectos, determinações contextuais ou pontos de vista não pudessem turvar o encontro -perfeitamente claro- com um mundo uniforme, e uniformemente dizível. Podemos identificar na noção de Zwischengliedern uma profilaxia contra a atitude de se buscar algum âmbito da linguagem ou do mundo cujos elementos não possam ser comparados com outros elementos de contextos mais ou menos aparentados. Afinal, é ao ser aplicada em cooperação com a noção de ligações intermediárias que aquela de sistemas proposicionais isolados (Satzsysteme) será relativizada.

Mas talvez seja útil, ainda, ao estabelecimento da importância da noção de 'ligações intermediárias', particularmente para a compreensão do que gostaríamos de chamar de segundo paradigma de análise conceitual de Wittgenstein, ${ }^{2}$ que se mencionem duas ambiguidades - ou, menos

${ }^{2} \mathrm{O}$ primeiro paradigma apontaria para uma distinção fundamental que dá 0 arranque à estruturação do que Wittgenstein chamava de o seu novo método, qual seja, aquele entre 0 campo das regras e 0 campo de "diferenças muito gerais", mas em todo o caso exteriores ao campo das regras - e que não são objeto de representação linguística. Trata-se, neste momento, de compreender a maneira como as regras se organizam em sistemas (fechados, ou insulados), que põem os seus critérios da mesma maneira como um sistema de medidas organiza internamente a possibilidade de uma atribuição específica de medida. O segundo paradigma expandiria um pouco mais o contexto em que regras operam, e passa a lançar um olhar sobre os sistemas de regras na sua continuidade mútua. Trata-se, então, de extrapolar o âmbito de esclarecimento duma regra para sistemas que interferem uns nos outros, e se organizam eles próprios em grupos maiores. 0 conceito de jogo de linguagem é então introduzido para dar conta do modo aberto, e adequadamente vago, desse encadeamento. Num terceiro paradigma, a análise conceitual encontra os seus limites últimos no contexto amplíssimo da "forma de vida". Trata-se, aí, de investigar a maneira como as próprias regras -mesmo organizadas em sistemas com certo grau de continuidade- já não dão conta de perfazer um campo autônomo de constituintes da linguagem. Nesse momento, o fim de uma cadeia de razões passa a ser encontrado, mais do que numa regra, na própria prática que fornece densidade ao uso dessa regra. Mais do que isso: só a prática -o contexto institucional amplo da forma de vida- forma sistema em termos estritos. Em tal contexto, uma situação adequada (passende Situation) de uso (ÜG §10) não marca apenas um domínio numa cadeia de regras, mas, mais profundamente, o espaço no qual se desdobram as finalidades e convicções (PU $\S 607)$ da figura filosófica que Wittgenstein viria a chamar de homem razoável (ÜG §§19, 138-44). Será este, então, o derradeiro contexto em que se desenrola uma análise conceitual completa no sentido 
drasticamente, detalhes semânticos relativos a noções em torno às quais a operação de 'ligações intermediárias' orbita. Um desses detalhes prende-se com ‘jogo’ em 'jogo de linguagem’. A expressão ‘jogo de linguagem’ é introduzida, nas Investigações filosóficas, no §7. Ali, a extensão do conceito é desde logo explicitada: deve abarcar, por um lado, uma dimensão linguística em termos estritos (os sistemas de regras -particularmente no seu aspecto de abertura $^{3}$-, e a expressão simbólica desses sistemas), e, por outro lado, uma dimensão mais bem antropológica do aprendizado e do uso desses sistemas, desde os momentos preparatórios desse uso, até aos momentos do seu pleno funcionamento. A expressão 'jogo de linguagem' será convocada a trazer, por vezes, quer um, quer outro aspecto do seu semantismo, consoante a finalidade de cada contexto argumentativo. Por exemplo, a dado momento lemos que "O termo 'jogo de linguagem' deve aqui ressaltar que o falar da [de uma] linguagem é parte de uma atividade, ou de uma forma de vida” (PU §23). Noutros contextos, a noção de 'jogo' associada à linguagem acentua menos a dimensão de prática da linguagem (“das Sprechen der Sprache”) e mais ${ }^{4}$ uma sua dimensão, digamos, horizontal. Nesses momentos, focamos artificialmente a atenção no fato de que nos orientamos por aquela prática, em termos particularmente semânticos, em contextos nos quais é por via de comparações (mais precisas ou mais vagas) com outros usos, e por vezes até com outras notações, que um dado uso se esclarece. Pois só assim é possível visualizar melhor as suas fronteiras - e é pelas suas fronteiras (e não por

relevante para Wittgenstein (PU §133; cf. também PB I,1). Neste terceiro momento, o "novo método" realiza 0 seu derradeiro movimento analítico. A boa análise dependerá agora não apenas das comparações gramaticais conducentes à visão perspícua da geografia dos conceitos, mas sobretudo da integração do analista ao contexto institucional amplo de uso do conceito sob escrutínio. Contudo, não se trata de desistir de visar ao sentido essencial dos conceitos: trata-se de modificar a imagem do que conte como essência. Esta expansão última do campo criterial dos conceitos ao contexto institucional amplo (die Umgebung) da forma de vida modifica o que se entende como âmbito autônomo da linguagem. Em relativa correlação à referida divisão tripartite dos paradigmas de análise conceitual em Wittgenstein, diremos que a famosa máxima que alude à autonomia do simbolismo linguístico relativamente à empiria ou a um campo transcendental puro, "x deve falar por / cuidar de si própria", foi saturada, em diferentes momentos, pela lógica (TB 22/8/14), pela linguagem (PG I, §2) e, finalmente, pela prática (ÜG §139). Nesta mesma direção, o sistema de constituintes que perfaz o campo criterial de base do simbolismo linguístico -ou seja, o seu âmbito autônomo- pode ser identificado, em três momentos diferentes no filósofo, com as regras internas a sistemas de regras, com sistemas de regras diversamente integrados, i.e., jogos de linguagem, e, finalmente, com a Umgebung alargada da forma de vida, o contexto institucional da praxis. Tal é o pano de fundo interpretativo do presente artigo.

${ }^{3} \mathrm{Ou}$ seja, relativamente à existência de relações inferenciais entre os sistemas, e não apenas no seu interior.

${ }^{4} \mathrm{Ou}$ seja, não excludentemente - até porque se trata de níveis lógicos diferentes. 
algum tipo de visualização da sua substância) que temos acesso à sua essência. Fica claro, então, que o papel coadjuvante da noção de 'ligações intermediárias' é fundamental, senão ao primeiro, pelo menos ao segundo aspecto relevante do semantismo de 'jogo de linguagem' - este um dos centros de gravidade da constelação conceitual do Álbum filosófico. ${ }^{5}$

A outra ambiguidade que gostaríamos de mencionar -sempre como forma de chamar atenção para a importância da noção de 'ligação intermediária'- incide sobre o próprio conceito de gramática. É quase demasiado sutil para ser de alguma utilidade. Vejamos o que diz Wittgenstein sobre certas imagens associadas à interpretação de uma ordem que fosse expressa por uma só palavra (“Lajota!”):

A frase não é 'elíptica' por deixar de fora alguma coisa em que pensemos quando a pronunciamos, mas porque é abreviada em comparação com um determinado paradigma da nossa gramática. ${ }^{6}$ (PU §20; grifo nosso)

A que determinado paradigma se refere o filósofo? Provavelmente àquele de comandos que são proferidos por meio da pronúncia de frases vistas como completas, particularmente com o uso de verbos no caso imperativo. Falar-se em paradigma (Vorbild), contudo, parece apontar para algo de mais importante do que uma escolha à primeira vista inócua: aquela de se usar uma oração (um enunciado organizado em torno a um verbo) ou uma frase (um enunciado organizado em torno a um substantivo, adjetivo, etc.) ali onde ambas podem atingir, para o que interessa, os mesmíssimos objetivos. De fato, se se tratasse de linguística, talvez a expressão 'paradigma' soasse aqui um tanto

\footnotetext{
${ }^{5}$ Álbum filosófico, como se sabe, é a metáfora com que Wittgentein se refere à sua maneira de composição, parte essencial do seu "novo método". A metáfora alude indiretamente à peculiaridade da natureza sistemática da forma de trabalho do filósofo. A ideia de que as regras são "o que há de último" (DW/S, p. 188) é um dos marcos centrais de arranque da segunda Denkweise de Wittgenstein. 0 atributo de autonomia acomoda-se bem a esse estatuto de fim das cadeias de razões que recebem, então, as regras. O mesmo já não se poderá dizer, talvez, de um seu outro traço fundamental: 0 de convidarem a um procedimento analítico casuístico. A esse respeito -e muito para além do fato de que 0 filósofo nunca deixou de efetivamente usar o vocábulo 'sistema' e suas declinações-, não será inútil assinalar que sistema, em Wittgenstein, se aproxima do seu sentido antigo. Segundo Pierre Hadot (2001, p. 148), entre os gregos o termo designava simplesmente "não um edifício de pensamentos, mas uma totalidade organizada cujas partes dependem umas das outras". O Álbum filosófico é sistemático nesse sentido antigo. Para o conceito de Álbum em Wittgenstein, cf. Moreno (2009).

${ }^{6}{ }_{m}$ Elliptisch' ist der Satz nicht, weil er etwas auslässt, was wir meinen, wenn wir ihn aussprechen, sondern weil er gekürzt ist - im Vergleich mit einem bestimmten Vorbild unserer Grammatik."
} 
exagerada. Mas é de filosofia que se trata na passagem; e, em se tratando de Wittgenstein, o leitor aprende, com o tempo, a não negligenciar a sua escolha das palavras, por mais sutil que pareça a opção feita. A sequência do parágrafo daria razão uma vez mais ao leitor paciente, com a introdução de novas vozes no diálogo. Não se tratava de uma escolha inócua entre expressões do mesmo: uma comparação inadequada entre maneiras de falar pode, efetivamente, conduzir a uma nuvem de hipostasias filosóficas. Bem mereceram, nesse caso, essas maneiras o apodo mais chamativo de paradigmas. $\mathrm{O}$ veículo de condensação da nuvem filosófica, aqui, foi o fato de que dois enunciados -um completo e um elíptico- possam veicular o mesmo significado sem que, num deles (no caso, o enunciado elíptico), o significado veiculado receba uma expressão verbal. Ora, há então significados que não recebem expressão verbal! Assim, o espanto diante de uma imagem sugerida por uma inocente ligação intermediária inadequada (i.e., uma comparação segundo aspectos que, ao serem aproximados, sugerem equívocos quanto ao uso das expressões comparadas) abre todo um campo de investigação novo. Novo - e profundo! Afinal, trata-se de descobrir onde reside uma coisa que deve estar ali, mas não se vê como. E não uma coisa qualquer, mas algo extremamente importante para nós: o significado das palavras. Mais ainda: o significado de 'significado'!

O paradigma da citação anterior diz-se "da nossa gramática”. Aqui, a "nossa gramática" é o repositório de uma dimensão holística; é o todo de que é parte "um determinado paradigma", mas no sentido em que todos o são (tautologicamente): o paradigma de "ordens completas" tanto quanto o paradigma de "ordens elípticas". Poderíamos dizer que a "nossa gramática", aqui, recebe como que um sinal de mais. $\mathrm{Ou}$, se se quiser: não há problema nenhum com a "nossa gramática"; todo o problema residiu na comparação feita entre dois tipos de uso, comparação que se veio a mostrar inadequada. $\mathrm{Ou}$ melhor ainda, inadequadas foram, não a comparação per se, mas, antes, determinadas evocações geradas a partir dela, que assumiram contornos aporéticos, misteriosos. $\mathrm{O}$ aspecto escolhido para interpretar uma ligação intermediária fez, aí, toda a diferença: por um lado, o aspecto de uma abreviação (no caso de uma voz filosófica do diálogo), e por outro lado o aspecto de um corpo de significação (Bedeutungskörper) passado em silêncio, mas que deve acompanhar a enunciação da ordem abreviada de alguma maneira que, agora, deve ser explicada pelo filósofo (no caso da outra voz filosófica). Com esse aspecto de "nossa gramática" em mente -ou seja, o todo de que são partes os paradigmas, todo esse do qual, nesse contexto, não faz sentido 
dizer que lhe falta nada-, vejamos agora uma outra ocorrência da mesma expressão:

Uma das fontes principais da nossa falta de compreensão é que não temos uma visão panorâmica do uso das nossas palavras. - A nossa gramática é falta em [é desprovida de] perspicuidade. ${ }^{7}$ (PU §122; grifo nosso)

A "nossa gramática" é tanto aquilo que partilhamos no uso do dia-adia, irrefletidamente -ou seja, sem análise-, quanto aquilo que ressaltamos por via da análise conceitual mas que no $§ 122$ se diz que, justamente, falta à "nossa gramática" (i.e., perspicuidade). Pois é a essência de um uso que deve ser fornecida pelo trabalho de representação perspícua - e a essência é dada pela gramática, ou seja, na gramática. Mas se é assim, subitamente soa estranha a queixa expressa no $\$ 122$ relativamente à gramática. $\mathrm{O}$ antigo problema da possibilidade de uma metalinguagem se complica infinitamente - como tantos antigos problemas ao serem acomodados no contexto da nova maneira de pensar (Denkweise) do filósofo. Não obstante, tal como no caso de muitas complicações para as quais não vemos um fim, a solução para esta pode ser dada por um gesto simples.

A ambiguidade ressaltada, sutil demasiado sutil -quase um forçamento- de "a nossa gramática”, serve a um propósito: indicar que, justamente, o problema da possibilidade ou não de uma metalinguagem, no contexto dos jogos de linguagem, só se põe quando não compreendemos a finalidade e os objetos de uma análise conceitual no ambiente de sistemas de regras abertos. A sequência do parágrafo anterior é explícita, ainda que sumária. Retomemos do seu início:

Uma das fontes principais da nossa falta de compreensão é que não temos uma visão panorâmica do uso das nossas palavras. A nossa gramática é desprovida de perspicuidade. - A representação panorâmica permite a compreensão que consiste justamente em "ver as conexões". Daí a importância da descoberta e da invenção de ligações intermediárias. (PU §122)

${ }^{7}$ „ES ist eine Hauptquelle unseres Unverständnisses, dass wir den Gebrauch unserer Wörter nicht übersehen. - Unserer Grammatik fehlt es an Übersichtlichkeit". 
O que nos interessa ressaltar aqui é menos a noção de representação panorâmica, e mais os passos na sua direção. Ou seja, é menos a Darstellungsform, a forma em que consiste a representação adequada no "novo método" pós-tractariano (i.e, justamente, panorâmica), e mais o próprio procedimento desse método. Como adiantamos acima, é nas Zwischengliedern, nas ligações intermediárias que identificamos o essencial desse procedimento. É por via dessas últimas que a atitude de se dispor a ver as conexões esclarecedoras de um dado uso encontra um encaminhamento efetivo, encontra o seu business ("Sache der Philosophie", PU §125). Tal como alguém que, perdido numa zona estranha da cidade, se dispõe a aquietar a sua angústia de desorientação, e assim liberar o foco do olhar para o entorno, identificando objetivamente as entradas e saídas e, sobretudo, as direções que por estas se pode (ou se deve) tomar. Uma paralisia do pensamento é capaz de encontrar, assim, uma saída.

Por exemplo, o 'problema da identidade na diferença' pode ser levado a desaparecer ao se adotar uma notação na qual 'e' é substituído, em alguns contextos, por ' $=$ ' e em outros por ' ' (que simboliza pertença a um conjunto). Exibir essa possibilidade lado a lado com o nosso uso da palavra 'é' basta para quebrar o encantamento da forma de representação da nossa linguagem. "Era o sistema de expressão que me mantinha cativo" ["Es war das System der Ausdrucks, welches mich in Bann hielt”] (TS 220, §99b). (Baker 1991, p. 30)

Apresentar novos aspectos de um dado uso é, portanto, um caminho possível para quebrar o encantamento de uma imagem que nos paralise com o seu mistério, com a sua aporia. Entre '=', ' ' e o nosso uso cotidiano de 'é, dão-se a ver ligações, possibilidades, que uma imagem forte tenderia a encobrir - quer por redução das possibilidades a uma só, quer pelo baralhamento da diversidade dos aspectos. Um dos resultados da descoberta, ou mesmo invenção, de ligações intermediárias possíveis é dar a ver claramente essa diversidade tal como ela objetivamente se pode exibir no simbolismo (mesmo que de maneira ficcional; o que é relevante é a possibilidade lógica objetiva).

Outro resultado é abrir o olhar, ou seja, abrir o espírito, para a rede que se forma entre os aspectos. Ao treinar-se o olhar para uma tal forma de representação, de alguma maneira se treina o pensamento a estar melhor 
aparatado para lidar com novas paralisias, novas imagens enfeitiçadoras. Como qualquer treino, este pode, é claro, falhar. De resto, e para retornar à metáfora da orientação urbana, a percepção de que um dado cruzamento de vias está ligado, por transições, a todos os demais (o que quer que signifique 'todos') não pode passar disto: um sentimento. "É isto uma 'Weltanschauung'?", pergunta-se Wittgenstein mais adiante no mesmo §122, acerca do conceito ("fundamental”) de representação perspícua, i.e, a sua nova maneira de "ver as coisas" (ib.). Melhor talvez será dizer: é uma atitude que passa a dirigir o olhar, a dirigir o pensamento. ${ }^{8}$

Essa direção tem, portanto, uma dupla incidência terapêutica. Por um lado, ela incide sobre o próprio olhar. Nesse caso, trata-se de "fazer justiça aos fatos” (BF, p. 129), i.e., tornar claramente visível (übersehbar zu machen) um estado de coisas (Zustand) relativo a dado uso do simbolismo e, portanto, a uma forma de vida. Por outro lado, a nova direção incide sobre o sentimento relativo a esse estado de coisas, inquietado (beunruhigt) por uma orientação dogmática que terá originado um olhar falto de perspicuidade (i.e, falto de observância das conexões entre os jogos). 'Espírito' (Geist) e 'objetividade' começam, já o vemos, a tornar-se imbricados de maneiras cada vez mais complicadas. Mas o instrumento efetivo de atuação ao serviço da atitude antidogmática, encontramo-lo nas ligações intermediárias entre os usos.

A ampliação crescente, por parte de Wittgenstein, do contexto criterial dos conceitos no sentido de abranger a sistematicidade aberta entre os jogos de linguagem e, posteriormente, a sua ancoragem na forma de vida leva a uma progressiva modificação da aplicação dos conceitos de 'regra' e de 'uso'. Regras continuarão a ser técnicas procedurais que regimentam jogos de linguagem, mas agora o fazem mantendo entre si um modo de influência mútua, com certa abertura e flexibilidade dos sistemas de regras - ou seja, por via de semelhanças e diferenças que lhes conferem uma identidade vaga, conquanto suficiente. $\mathrm{O}$ uso ou legitimação de uma regra passa a ser entendido como ganhando relevo no contexto das fronteiras entre os sistemas de regras - e, no limite, a partir de uma prática de tal maneira complicada e

${ }^{8}$ David Stern (1995) chamou a uma tal atitude holismo prático. Mais tarde relativizou-a (Stern 2004), no contexto do diálogo do álbum filosófico, para atribuí-la apenas a uma determinada voz filosófica do álbum. Trata-se de uma voz que intervém ao ser confrontada com um interlocutor que, persuadido embora da importância da prática, tende a encaminhar o business filosófico na direção de uma teoria dessa Praxis. O recuo do "narrador wittgensteiniano" era então esperável: "O pano de fundo é o azáfama da vida" ("Der Hintergrund ist das Getriebe des Lebens", BPP II, §625). 
ampla que a própria análise das regras não chega para dar conta delas em termos satisfatórios. A questão que então se há de pôr, cada vez mais, é aquela da natureza da legitimação dos usos, que se confunde com a questão da natureza da pragmática wittgensteiniana: na teia ou, melhor, na corda (PU $\S 67)$ dos jogos de linguagem, como podemos falar com clareza de certeza e critérios, e verdade qualificada? Aqui se conectam, então, as aparentes aporias da arbitrariedade e da necessidade da regra em Wittgenstein. E a pragmática wittgensteiniana se abre, nas sugestões que nos deixa, para o problema da racionalidade (não propriamente da Razão!) e da legitimação (não propriamente do Poder!), e para uma interlocução profícua com outras tradições e estilos (tais como a pragmatista e certas correntes analíticas avessas à ampliação radical do ambiente criterial operado pelo último Wittgenstein). Oferece, nesse contexto, sugestões bastante singulares à prática filosófica. $\mathrm{O}$ essencial do método filosófico encontramo-lo, aqui, na análise conceitual, e na maneira como esta se abriu para integrar no seu campo objetivo, ou formal, elementos da vivência da forma de vida. Tal abertura, ao ressaltar o lugar dado ao conceito e à forma de vida na construção do conhecimento em geral, favorece, ainda, um contraste esclarecedor entre uma pragmática de inspiração wittgensteiniana e certas correntes espontaneístas em educação (usualmente identificadas com a tradição construtivista) e certos novos chamados a um universalismo da Razão. Vejamos alguns aspectos desse lugar do conceito (e da forma de vida) na construção do conhecimento filosófico contra o pano de fundo de recentes caminhos de destituição sua-, para em seguida concluirmos retornando às ligações intermediárias.

Quando Paul Hacker escreve o volume final, de 1996, da monumental série de comentários às Investigações filosóficas, elaborada ao longo de 26 anos conjuntamente com Gordon Baker (salvo nos trabalhos finais), ele decide abrir o volume com um estudo acerca das noções de análise e de conceito, particularmente em Moore e Russell - e também com essas mesmas noções encerra o volume. E é interessante que o faça no âmbito de uma tematização da filosofia em sentido amplo, como atividade presente e como uma prática que tem uma história. As mutações nas concepções de análise conceitual que Hacker recenseia são postas em paralelo a uma oposição geral relativa ao sentido do trabalho filosófico. Por um lado, uma concepção de filosofia como contribuição ao conhecimento de estruturas supostamente desconhecidas do pensamento, estruturas essas que seriam reveladas através de diferentes procedimentos de análise. Por outro lado, uma concepção de 
filosofia como esclarecimento conceitual com fins específicos, casuísticos, regionais. Na base desta oposição estaria uma imagem da linguagem segundo a qual a linguagem representa como que um obstáculo ao pensamento, à medida que as formas subjacentes do pensamento não encontrariam representação adequada nas formas superficiais da linguagem. Na perspectiva de tal imagem, uma filosofia da lógica deve sanar este problema, de maneira a chegar a esclarecer de uma vez por todas o poder expressivo virtualmente infinito das proposições legítimas - ou seja, esclarecer a produtividade semântica da linguagem. Tal filosofia deve, portanto, cumprir duas tarefas que não se acomodam muito bem uma à outra: fornecer conhecimento novo e fornecer conhecimento definitivo.

Que este é um caminho que favorece a proliferação de metáforas enganosas acerca do sentido em geral, e para o processo de ensino e aprendizagem em particular, é algo que é confirmado pela tendência a gerar uma fusão entre conhecimento e esclarecimento (ou entendimento) - ou, se se quiser, entre informação e conhecimento. E é agravado, do ponto de vista wittgensteiniano, por certas interpretações de recentes sucessos das ciências cognitivas em representar processos físicos do cérebro - segundo as quais essas representações forneceriam mapas conceituais produzidos mecanicamente. Um círculo parece fechar-se, na gestação de certa cultura filosófica moderna, com a criação de "laboratórios metafísicos" cujos resultados, por sua vez, se espera que alimentem máquinas com informações que permitam a estas últimas computar conceitos. Como se a natureza interna das ligações intermediárias entre os conceitos fosse, não gramatical mas, antes, puramente informacional num sentido representável por tabelas de correlações mecânicas. Aplicações possíveis dessas máquinas virtuais são os tradutores automáticos e os motores de busca ditos inteligentes, que calculem tendências de interesses e adesões (a associações entre conceitos - permitindo, a partir daí, induções de toda a sorte, aplicadas em campos os mais diversos).

A ninguém ofende, por si só, o chamar-se um programa de computador de tradutor automático, assim como não há problema em se realizar varreduras dos processos cerebrais e correlacionar os resultados com figuras e gráficos. O problema começa quando nos fascinamos com essas realizações técnicas, e por via desse fascínio começamos a aproximar noções que se repelem, a baralhar níveis lógicos entre objetos que não convivem conceitualmente nos mesmos ambientes - numa palavra: a violar os usos das palavras num sentido que paralise a orientação do entendimento. Ora, tudo 
nos convida a isso, num tempo em que apenas adições ao conhecimento se legitimam como movimentos do pensamento (por oposição a aprofundamento e variação de aspectos). Relega-se, assim, a elucidação do que já sabemos mas parecemos constantemente deixar de reconhecer claramente (i.e., a nossa inserção na forma de vida, os sistemas de crença e de verificação de base) a mero divertimento de chá das cinco, na britânica expressão de Russell. De fato, como diz Paul Hacker no último parágrafo do seu Comentário Analítico, o trabalho intelectual que não se ocupe com novas construções mas, antes, com a visão perspícua de construções possíveis -ou seja, a clareza como um fim em si mesmo-, perde, então, o seu lugar.

Numa perspectiva alternativa a essa, a análise conceitual é o locus da filosofia. É menos um seu paradigma do que um instrumento ao serviço do estudo da gramática dos nossos conceitos com determinados fins, fins de clarificação ali onde perdemos a capacidade de identificar de maneira claramente explicitável -verbalmente explicitável- os objetos de que falamos, e cuja identificação e atributos podemos querer ensinar. A inspiração wittgensteiniana dessa perspectiva ganha muito em seguir os passos do filósofo no refinamento dos seus instrumentos de trabalho, ao serviço de um objetivo que se confundia, para ele, com a filosofia: a terapia filosófica do pensamento paralisado por abusos lógicos da linguagem.

Quisemos ressaltar a importância de um desses instrumentos de trabalho, talvez imerecidamente negligenciado. Pois a diversidade de cenas panorâmicas da forma de representação do "novo método" de Wittgenstein (porventura uma Weltanschauung!) não apenas inclui casos intermediários, de forma então, dir-se-ia, acessória: é, também, constituída por estes. 


\section{Referências}

NB: A data entre parênteses a seguir ao autor é a da primeira publicação do texto citado. A não ocorrência de uma segunda data significa que se compulsou a edição relativa à primeira data, ou um seu fac-símile digital.

BAKER, G. (1991). Philosophical Investigations §122: Neglected Aspects. In:

Wittgenstein's Method: Neglected Aspects. Ed. e intr. Katherine Morris. Malden, MA: Blackwell, 2004, pp. 22-51.

FREGE, G. (1884). Os fundamentos da aritmética. Sel. e tr. Luís H. L. dos Santos. In: Peirce/Frege. Sel. Armando M. d’Oliveira. SP: Nova Cultural (“Os Pensadores”), 1983, pp. 197-276.

HACKER, P. M. S. (1996). Wittgenstein's Place in Twentieth-Century Analytic Philosophy. Oxford/Malden: Blackwell.

HADOT, P. (2001). La philosophie comme manière de vivre. Paris: Albin Michel. MORENO, A. R. (1995). Wittgenstein: através das imagens. 2º ed. Campinas: Ed. da Unicamp. . (2005). Introdução a uma pragmática filosófica. Campinas: Ed. da Unicamp. (org.). (2009). Como ler o Álbum?. Campinas: Unicamp/Centro de Lógica, Epistemologia e História da Ciênica ("Coleção CLE” n.55).

RUSSELL, B. (1913). O lugar da ciência na educação liberal. In: Misticismo e lógica e outros ensaios. Tr. Alberto Oliva et al. RJ: Zahar, 1977, pp. 41-54.

STERN, D. (1995). Wittgenstein on Mind and Language. NY/Oxf.: Oxford U.P. . (2004). Wittgenstein's Philosophical Investigations - An Introduction.

Cambridge: Cambridge U.P.

\section{Referências - Wittgenstein}

Obs.: A referência dos Datiloscritos (DS) e Manuscritos (MS) citados é o Nachlass (N). DS $213=$ Big Typescript.

BF - Remarks on Frazer's Golden Bough / Bemerkungen über Frazers Golden Bough. Ed. bil. In: PO, pp. 118-154. 
BPP1 / BPP2 - Remarks on the Philosophy of Psychology / Bemerkungen über die Philosophie der Psychologie. 2 vols. Ed. bil. Ed. G.E.M. Anscombe e G.H. von Wright, tr. G.E.M. Anscombe. The U. of Chicago P., 1980 (trad. bras. Observações sobre a filosofia da psicologia, tr. R. Machado, Ideias e Letras, 2008).

BT - Big Typescript. In: N (DS 213) (texto alemão e trad. inglesa: The Big Typescript German/English Scholars' Edition: TS 213. Ed. e tr. Grant Luckhardt e Maximilian Aue. Wiley-Blackwell, 2005. Trad. port. do cap. "Filosofia” por António Zilhão, in Manuscrito v.XVIII, n.2, Campinas, pp.1-37, 1995).

DW/S - Dictées de Wittgenstein à Waismann et pour Schlick I - Textes inédits - années 1930. Ed. A. Soulez, org. G. Baker, tr. C. Chauviré et al. Paris: PUF, 1997 (texto alemão e trad. inglesa The Voices of Wittgenstein - The Vienna Circle, ed. Gordon Baker, Routledge, 2003).

$\mathrm{N}$ - Wittgenstein's Nachlass - The Bergen Electronic Edition. Oxford U.P./Univ. of Bergen, 2000.

PB - Philosophische Bemerkungen. Ed. Rush Rhees. Frankfurt: Suhrkamp, 1970 (tr. inglesa Philosophical Remarks, tr. R. Hargreaves e R. White, Blackwell, 1975).

PG - Philosophische Grammatik. Ed. Rush Rhees. Frankfurt: Suhrkamp, 1973 (tr. inglesa Philosophical Grammar, tr. A. Kenny, U. of California Press, 1974).

PO - Philosophical Occasions 1912-1951. Ed. J. Klagge e A. Nordmann. Indianápolis: Hackett, 1993.

PU - Philosophical Investigations / Philosophische Untersuchungen. $3^{\circ}$ ed. bil. Ed. R. Rhees e G.E.M. Anscombe, tr. G.E.M. Anscombe. Blackwell, 2001 (tr. bras. Investigações Filosóficas - Wittgenstein, $5^{\circ}$ ed., tr. J.C. Bruni, SP: Nova Cultural (“Os Pensadores”), 2001; tr. port. M.S. Lourenço, $2^{\circ}$ ed., Gulbenkian, 1995).

TLP - Tractatus Logico-Philosophicus. $2^{\circ}$ ed. bil.. Tr. e apresentação. L.H.L. dos Santos. SP: Edusp, 1994.

ÜG - Da certeza / Über Gewissheit. Ed. bil. Ed. G.H. von Wright e G.E.M. Anscombe, tr. M. E. Costa. Lisboa: Ed. 70, 1990. 